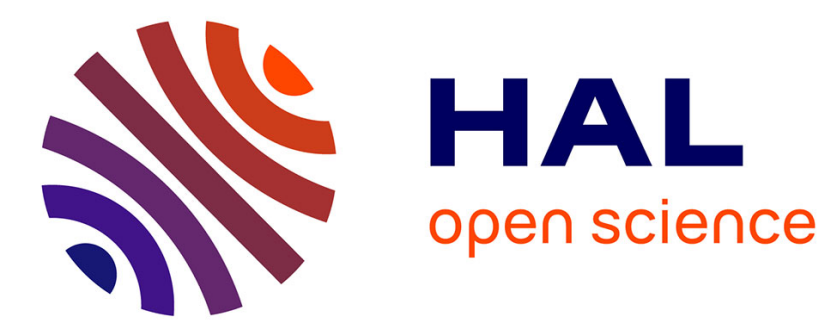

\title{
The analysis of thermal comfort requirement through the simulation of an occupied building
}

\author{
Francoise Thellier, Alain Cordier, Francoise Monchoux
}

\section{To cite this version:}

Francoise Thellier, Alain Cordier, Francoise Monchoux. The analysis of thermal comfort requirement through the simulation of an occupied building. Ergonomics, 1989, 10.1080/00140139408963691 . hal-02180920

\section{HAL Id: hal-02180920 \\ https://hal.science/hal-02180920}

Submitted on 11 Jul 2019

HAL is a multi-disciplinary open access archive for the deposit and dissemination of scientific research documents, whether they are published or not. The documents may come from teaching and research institutions in France or abroad, or from public or private research centers.
L'archive ouverte pluridisciplinaire HAL, est destinée au dépôt et à la diffusion de documents scientifiques de niveau recherche, publiés ou non, émanant des établissements d'enseignement et de recherche français ou étrangers, des laboratoires publics ou privés. 
archives-ouvertes

\section{The analysis of thermal comfort requirement through the simulation of an occupied building}

Francoise Thellier, Alain Cordier, Francoise Monchoux

\section{To cite this version:}

Francoise Thellier, Alain Cordier, Francoise Monchoux. The analysis of thermal comfort requirement through the simulation of an occupied building. Ergonomics, Taylor

Francis, 1989, 10.1080/00140139408963691 . hal-02180920

\section{HAL Id: hal-02180920 \\ https://hal.archives-ouvertes.fr/hal-02180920}

Submitted on 11 Jul 2019

HAL is a multi-disciplinary open access archive for the deposit and dissemination of scientific research documents, whether they are published or not. The documents may come from teaching and research institutions in France or abroad, or from public or private research centers.
L'archive ouverte pluridisciplinaire HAL, est destinée au dépôt et à la diffusion de documents scientifiques de niveau recherche, publiés ou non, émanant des établissements d'enseignement et de recherche français ou étrangers, des laboratoires publics ou privés. 


\title{
The analysis of thermal comfort requirements through the simulation of an occupied building
}

\author{
F. Thellier, A. Cordier and F. Monchoux \\ Laboratoire Energie Solaire et Thermique de l'Habitat, Universizé Paul Sabatier. \\ 118 route de Narbonne, 31062 Toulouse Cedex, France \\ Keywords: Building; Human thermophysiology; Thermal model; Skin temperature; \\ Local discomfort.

\begin{abstract}
Building simulation usually focuses on the study of physical indoor parameters, but we must not forget the main aim of a house: to provide comfort to the occupants. This study was undertaken in order to build a complete tool to model thermal behaviour that will enable the prediction of thermal sensations of humans in a real environment. A human thermoregulation model was added to TRNSYS, a building simulation program. For our purposes, improvements had to be made to the original physiological model, by refining the calculation of all heat exchanges with the environment and adding a representation of clothes. This paper briefly describes the program, its modifications, and compares its results with experimental ones. An example of potential use is given, which points out the usefulness of such models in seeking the best solutions to reach optimal environmental conditions for global, and specially local comfort, of building
\end{abstract} \\ occupants.
}

\section{Introduction}

Improvements in heating and air conditioning systems require a simultaneous development of comfort studies. Most of these studies can be performed by modelling. Available software can be used for empty buildings, including (or excluding) the basic parameters necessary to judge comfort requirements, but these programs very seldom represent an occupied building, even though thermal models of the human body are now available. In this study, we added such a model to a building simulation program, called TRNSYS (Klein 1988).

TRNSYS is composed of a series of subroutines, called 'types', linked together through an iterative process. Some are used for in put-output purposes (data reading, printing results, etc.), some to perform calculations (differential equations, additions, etc.), and some are individual models of each component of the thermal system (walls, windows, etc.). The human body model is from this last group. TRNSYS combines the physical or physiological data characterizing the weather, the house with its heating system, and the body of the occupant, so illuminating aspects of human thermal behaviour within a house.

This study has been performed with the close collaborative help of physiologists and psychologists, and our models have been validated through experiments carried out at the LPPE/CNRS-(Laboratoire Physiologie et Psychologie Environnementales) (Thellier et al. 1989).

\section{A model of the human body}

\subsection{The human thermoregulation model}

Over the past 20 years, many papers have been published describing thermal models 


\section{F. Thellier et al.}

of the human body. Those models, based upon empirical or mathematical methods, predict the thermal behaviour of the body in steady or unsteady states. The body is usually divided into segments, sometimes more than 200 in some models.

The simplest models are frequently for steady state, and used to calculate comfort indices. The most complex ones have been written for specific physiological purposes, are often difficult to handle, and do not take real environments into account.

We chose the unsteady state 25 -node model written by Stolwijk et al. (1977). In this model, the body is divided into six segments (head, trunk, arms, hands, legs, feet), each composed of four layers (core, muscles, fat, skin). Blood links these 24 compartments. The defining parameters of which are given by the physical characteristics of a 'standard' man with a body weight of $74 \mathrm{~kg}$ and a skin surface area of $1.89 \mathrm{~m}^{2}$. Thermal balance is calculated for each node. New temperatures are determined and compared with set temperatures, and the results are gathered by the thermal regulator, which determines appropriate physiological reactions. Four kinds of reactions can take place: vasoconstriction and shivering against cold, vasodilation and sweating against heat. Local and mean skin temperature or dampness can then be used to estimate thermal sensations.

The thermal equilibrium of the body is obtained when all heat produced can be dissipated into the environment. When this is reached without significant physiological reactions, the body is said to be at thermal neutrality - a requirement for thermal comfort.

\subsection{The complete model}

The main reason that led us to choose this physiological model was that the partition of the body into six segments allows the study of local discomfort. In order to represent a man in a room exposed to real meteorological data, we had to make several modifications to the original model, where the environment was assumed to be isothermal and the body naked.

The modifications are described below; some are made in the model itself, while other modifications made necessary the addition of new 'types' to the original TRNSYS.

Convective heat exchange is computed from air temperature and relative air velocity, which are calculated by another 'type', for each part of the body, as a function of activity and/or the temperature gradient induced by the heating system.

Radiative heat exchanges were calculated previously through global coefficients and one mean radiant temperature. This procedure could mask problems such as local discomfort which can be induced by non-isothermal surfaces [Olesen 1970]. We created a new 'type' computing by the Monte-Carlo method, infra-red radiation exchanges between each surface of the body (seating or standing) and the room. It produces the radiative heat fluxes which are to be entered into the physiological model. Radiative temperature asymmetries are also available, so that the study of the influence of room geometry with its distribution of the cold and hot surfaces is possible.

The model itself has been improved by the addition of another layer representing clothes, which did not exist in the original model. The first step was to add a simple steady-state representation of clothes, which were considered as simple resistances to heat and humidity transfers. The present model includes water absorption and 
evaporation by the material, the 'pumping effect' due to movements, and their consequences during transients (Cordier 1989).

After comparisons with experiments some physiological parameters had to be changed, for example, local skin blood flow, work distribution in muscles, etc. Other heat exchanges were refined (respiration, coefficient of sweat evaporation, etc.) or added (conduction between feet and floor).

The complete model is far too complex to be represented by a clear block diagram. Figure 1 shows connections between the physiological model-renamed MARCL-and some of the new 'types'. The implementation of the human model in TRNSYS made possible the recycling of information, such as the body producing heat or water vapor, making sure that a real coupling between man and environment is achieved.

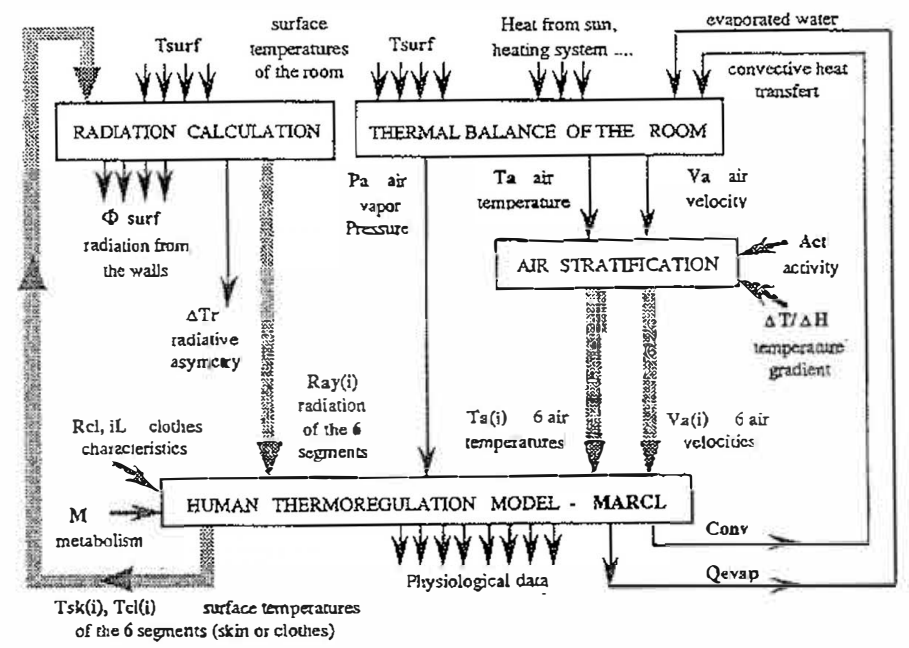

Figure 1. Connections between the physiological model-MARCL-and the other models of the building's elements.

\section{Validation}

Before using the model for real simulations, we compared its results with experimental ones in some simple configurations.

\subsection{Comparison with general results for mean skin temperature}

Mean skin temperature of the human body at rest versus air temperature has been measured by different authors (Meyer 1981); their conclusions usually lead to a linear relationship. Figure 2 shows the results of seven studies, along with those given by our model. Computed mean skin temperature always lies within the experimental range, even though it reaches the upper limit for an air temperature higher than $28^{\circ} \mathrm{C}$.

A change in the slope of the computed curve occurs between $26^{\circ} \mathrm{C}$ and $28^{\circ} \mathrm{C}$, when thermoregulation reactions against cold are changed into reactions against heat.

\subsection{Comparison with experiments}

In order to adjust the model more accurately, we compared its results to experimental ones. We performed simulations reproducing experiments done by 


\section{F. Thellier et al.}

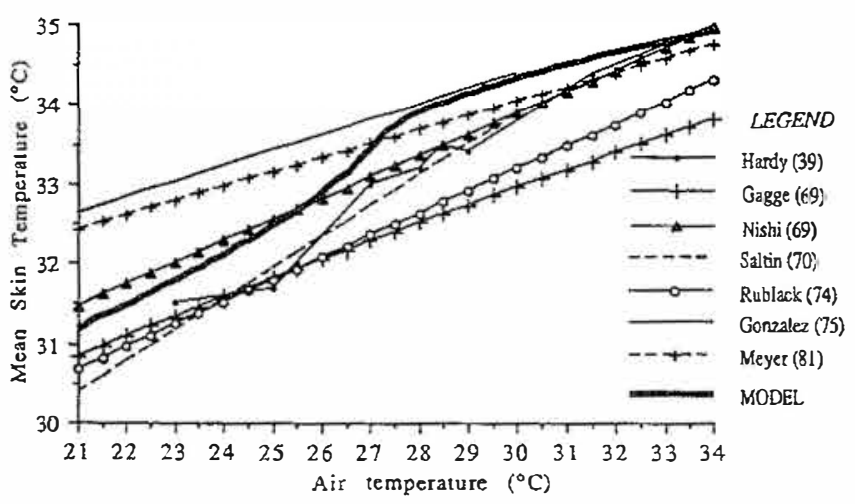

Figure 2. Mean skin temperature, as given by different authors and results of the model.

Grivel et al. (1989) in the LPPE. Though many experiments (Thellier 1989) have been used for comparison, only one is described here.

3.2.1. Experimental method: The experiment was carried out in a climatic chamber where thermal parameters could be controlled accurately and measured. Six nude men, three at a time, sat at rest in the chamber for $3 \mathrm{~h}$ answering questions about their thermal sensations.

Dew-point temperature and air velocity were maintained constant at $5^{\circ} \mathrm{C}$ and $0.25 \mathrm{~m} / \mathrm{s}$. Air and wall temperatures were equal and varied simultaneously, as shown in figure 3. After a $1 \mathrm{~h}$ period of thermoneutral conditions, the subjects were exposed for $160 \mathrm{~min}$ to air and wall temperature variations by a $2^{\circ} \mathrm{C}$ step every $8 \mathrm{~min}$.

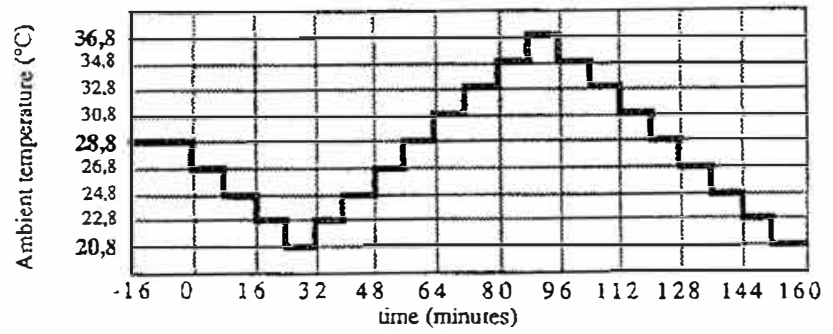

Figure 3. Experimental ambient temperature variations vs time.

During experiments, the following physiological variables were recorded: rectal temperature, 4 skin temperatures (chest, upper arms, thigh and calf), and mean skin temperature was then calculated by the Ramanathan method.

3.2.2. Modelling: Our model cannot run with three people at the same time, so we first computed the increase of mean radiant temperature on the studied subject due to the presence of the two others (Thellier 1989). It was found to be less than $0.3^{\circ} \mathrm{C}$, which is not enough to modify the thermal balance of the body.

In figure 4, the average experimental mean skin temperature and the corresponding computed value are shown, versus time. The agreement between computed and measured values is acceptable, and the slopes and amplitudes of 


\section{Building simulation}

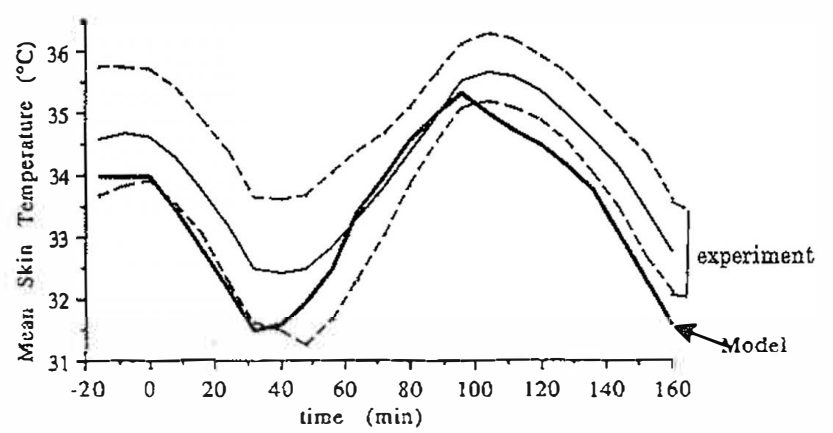

Figure 4. Mean skin temperature variations vs time, experimental (thin line), and computed results (thick line). The two dashed lines are the limits of the maximum inter-individual differences.

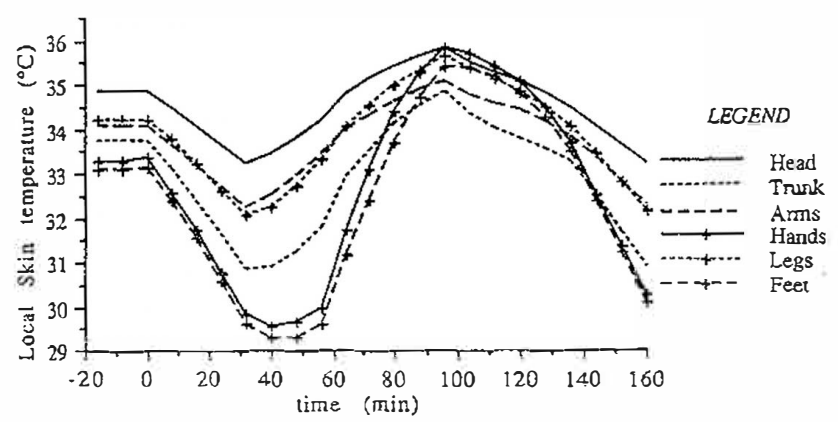

Figure 5. The six local skin temperatures, as given by the model.

variations are good, but the model seems to react faster than reality. This is probably due to the regulation system that has been determined with steady state experiments, and does fit with transient reactions because the dynamic sensitivity of the thermoreceptors-even though identified by many authors-has never been measured.

Mean skin temperature provides a good indication for overall thermal comfort but may hide problems of local discomfort. For example a low foot temperature can be balanced by a high arm temperature.

In figure 5, the six local skin temperatures are shown. It will be noticed that the hands and feet have a temperature swing greater than other parts because heat production and blood flow are less important in those segments; consequently they are influenced much more by climatic. changes.

Experimental data for the head, hands and feet were not available. So the comparisons with other experiments are only for trunk, arms, and legs (figure 6). In this figure, the temperatures of the six subjects are given. For legs and arms, experimental and computed curves are in good agreement. For the trunk, the simulated temperature is lower than the experimental one, but we must underline that skin temperature is averaged for the whole trunk, whereas the measurement is only made for the chest, which is usually warmer than the shoulders or the lower back (Olesen 1973). 


\section{F. Thellier et al.}
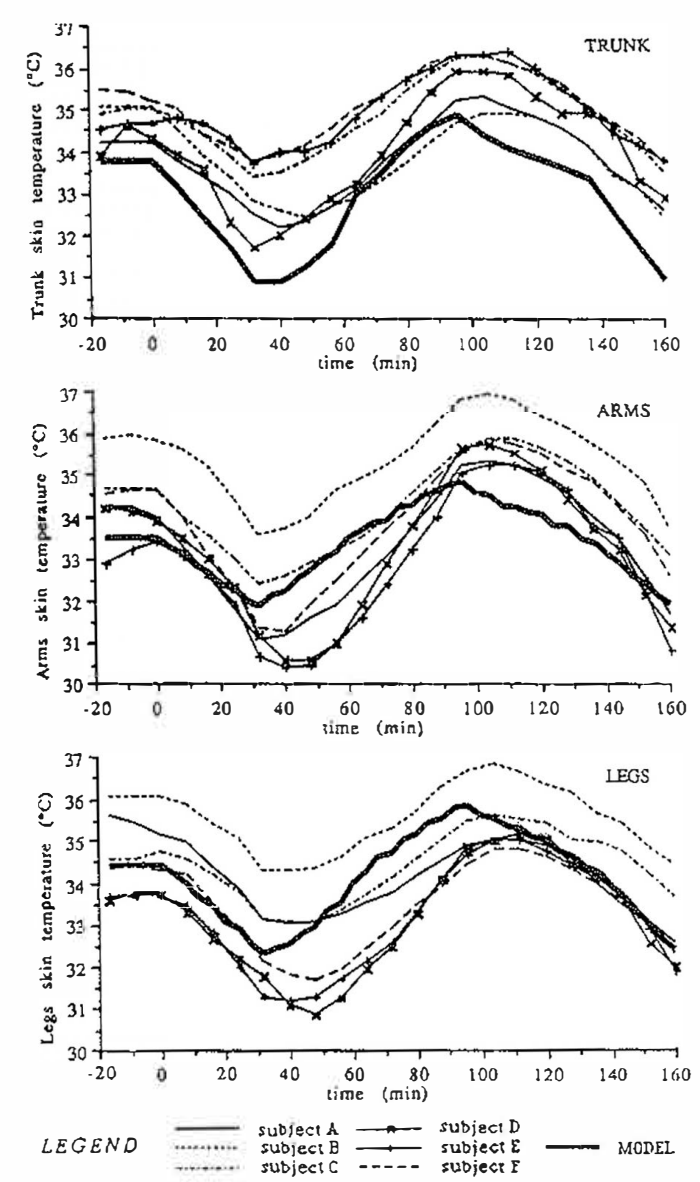

Figure 6. Local skin temperatures (1runk, arms and legs); comparison between experimental (thin and dashed lines) and simulated (thick lines).

\section{An example of simulation}

The software described previously has been used to simulate situations that may occur in a house and for which no experimental results are available. Effects of local draughts on the human body are presented here. Two cases were studied: a draught on feet, and on the head.

A sedentary nude man was placed in a room where the ambient temperature is set to $27.5^{\circ} \mathrm{C}$, and air velocity to $0.1 \mathrm{~m} / \mathrm{s}$; these conditions are suitable for thermal neutrality. At time 0 , a local cold draught was directed either on feet or on the head. The air velocity and air temperature of the draught were then respectively $V_{\text {drauglt }}=1 \mathrm{~m} / \mathrm{s}$ and $T_{\text {draught }}=25^{\circ} \mathrm{C}$. Figure 7 shows heat production and evaporative losses plotted versus time, for both cases.

Before the beginning of draught (time 0), slight reactions against warm can be seen: evaporative losses are not basal. From time 0, sweat evaporation decreases, more significantly for 'head-draught' (the broken shape of the 'feet-draught' curve comes from the oscillations of the physiological regulator model). Metabolism increases only for 'head-draught' simulation, because the body is reacting against 


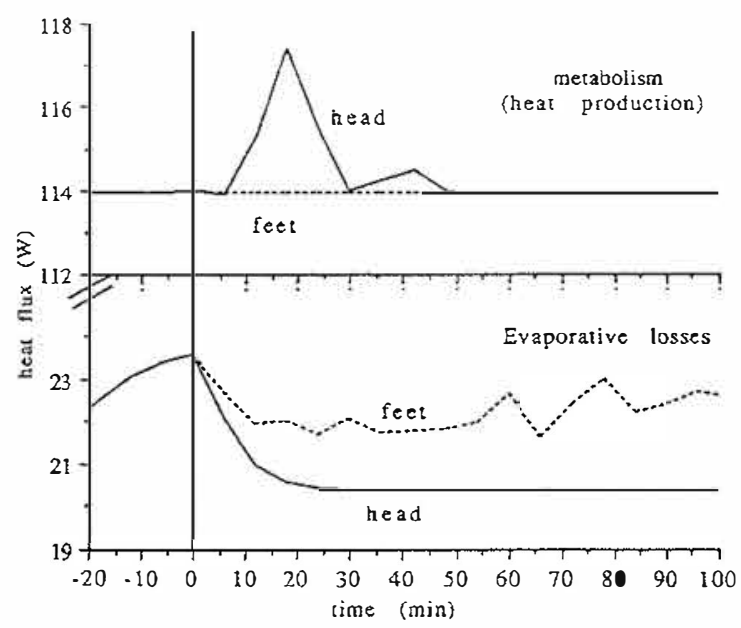

Figure 7. Metabolic heat production and evaporative heat losses comparison for the two draughts (on feet and on the head).

cold (shivering); it starts some minutes after time 0 . Three-quarters of an hour later, the body has reached a new equilibrium with basal sweat rate.

Even though feet and head have nearly the same skin area, the differences between those two simulation results come from the respective role of each part of the body in the control system, whose aim is to kecp the internal temperature
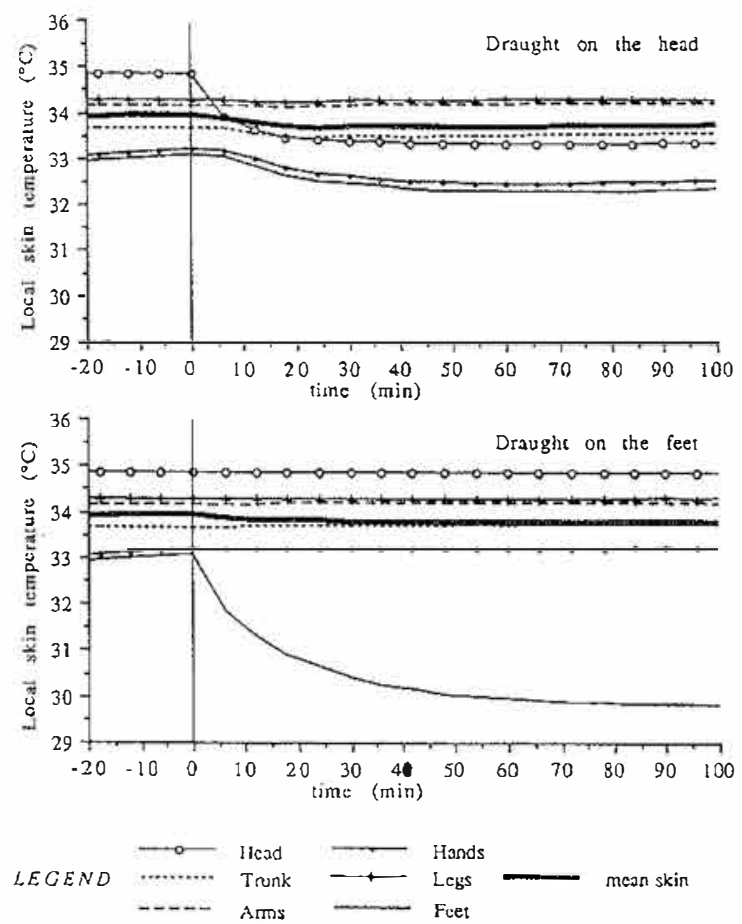

Figure 8. Mean and local skin temperatures vs time, for 'head-draught' and 'fect-draught'. 
constant, and especially that of the brain; thus the head plays a much more important role.

Local and mean skin temperatures computed are plotted in figure 8 for both cases. A comparison between the two sets of curves points out that even if the mean skin temperatures are very close, local skin temperatures are different.

For draught on feet, the only significant change is a $3^{\circ} \mathrm{C}$ drop for foot temperature, other temperatures remaining constant; the global heat balance of the body remains nearly unchanged.

For draught on head, most local temperatures decrease slightly. Head temperature is first lessened by $1.5^{\circ} \mathrm{C}$. A few minutes later, hands and feet temperatures decrease also, because cooling of the head skin leads to reactions against cold: first vasoconstriction inducing a decrease of hand and feet temperatures, then internal temperature is slightly enhanced by shivering. A new equilibrium is reached, with a new temperature partition and shivering stops because it is unnecessary.

In both cases mean skin temperature decrease is $0.3^{\circ} \mathrm{C}$, which is not enough to feel uncomfortable according to the 'usual' recommended 'neutral skin temperature limits' (Galéou 1989). Nevertheless, there may be a difference between them. In the 'feet-draught' case the mean temperature decrease is only due to a drop of $3^{\circ} \mathrm{C}$ of the feet skin temperature and may lead to local discomfort. In the 'head-draught' case, it comes from a simultaneous decrease of the head $\left(1.5^{\circ} \mathrm{C}\right)$ and hands and feet temperatures $\left(0.5^{\circ} \mathrm{C}\right)$, none of them being enough to be uncomfortable.

\section{Conclusion}

Local discomfort induced by heating systems or by architectural arrangements of a room can only be predicted by a detailed model which gives local physiological parameters of the human body and all the local interactions with the environment. Implementation of a detailed model through TRNSYS environment simplifies greatly the description of thermal surroundings and allows recycling of all data and the study of transient conditions. The body time constant can be nearly one hour which is close to the building time constant.

Such a model is obviously worthwhile but it entails computing all the thermal exchanges between man and environment which greatly complicates the problem. The examples shown in this paper show that the body thermoreactions can be quite different in cases only modestly distinguished. It appears that some physiological parameters can reach values which produce local discomfort and cause complaints.

The detailed model presented here allows the analysis of all requirements for local comfort. The model can be used with a detailed description of the surroundings (wall composition, etc.), or entering the global evolution of radiant and air temperatures, humidity and air velocity. The degree of sophistication of this description depends on what is needed.

This model will be followed up by the creation of another, which is currently under development. This latter will deduce local and global thermal sensations from physiological and physical results. This tool will allow us to study architectural, technical solutions, or energy management in a way that takes the individual into account.

\section{Acknowledgement}

This work has been supported by Plan Construction, Electricité de France, Gaz de France, and the AFME (French Agency for Energy Management). 
The authors thank J. F. Grivel and V. Candas from the LPPE (Laboratoire Physiologie et Psychologie Environnementales), Strasbourg, for their help and the experimental data.

\section{References}

Cordier, A., Derbel, H., Monchoux, F., Serin, G. and Thellier, F. 1989, Influence du vêtement sur le comfort thermique: modélisation en régime transitoire, Proceedings J.I.TH, 4th International Meeting on Heat Transfer, CNRS, 2, 645-651.

Galeou, M., Grivel, F. and Candas, V. 1989, Le confort thermique: aspects physiologiques et psychosensoriels. Etude bibliographique, Research Report CNRS/INRS, LPPE Strasbourg.

Grivel, F., Hoeft, A. and Candas, V. 1989, Body temperature and thermal perception during warm and cool periodic transients: influence of clothing, in A. Mital (ed.) Advances in Industrial Ergonomics and Safety. (Taylor \& Francis, London), 217-224.

KLeIN, S. H. and BeCKMAN, W. A. 1988, TRNSYS User's Manual, University of Wisconsin.

MeYer, J. P. 1981, Prévision de la température cutanée moyenne: effets des paramètres d'ambiance thermique, de l'exercice musculaire et de l'acclimatement à la chaleur, Medicine thesis, Strasbourg no 174.

Olesen, B. W. and Fanger, P. O. 1973, The skin temperature distribution for resting man in comfort, Archives des Sciences Physiologiques, 27, A385-A393.

Olesen, B. W., Mortensen, E., Thorsauge, J. and Berg-Munch, B. 1970, Thermal comfort in a room heated by different methods, ASHRAE Transactions, 86(1), 34-48.

STOLwIJk, J. A. J. and HARDY, J. D. 1977, Control of body temperature, Handbook of Physiology, Reactions to Environmental Agents, 9(4), 45-68.

Thellier, F. 1989, Modélisation du comportement thermique de l'homme et de son habitat. Une approche de l'étude du confort, PhD dissertation, Toulouse no 510, Université Paul Sabatier, France.

Thellier, F., Cordier, A., Monchoux, F., Serin, G., Grivel, F. and Candas, V. 1989, Influence de l'environnement sur le corps humain: modélisation d'un bâtiment occupé, Proceedings C.I.B. 89, Xith International Congress, 1, 321-328. 